\title{
Perception of Tuberculosis Treatment in Tribal area of Akole Block of Ahmednagar, Maharashtra
}

\author{
Afwan Khan', Swanand Tilekar ${ }^{2}$, Sunil Thitame ${ }^{3}$, Somasundaram Konduri ${ }^{4}$ \\ Pravara Institute of Medical Science, Loni, Ahmednagar Maharashtra, India \\ Professor, Centre For Social Medicine, Pravara Institute of Medical Science, Loni, Ahmednagar Maharashtra, India \\ Assistant Professor, Centre For Social Medicine, Pravara Institute of Medical Science, Loni, Ahmednagar Maharashtra, India \\ Professor, Centre For Social Medicine, Pravara Institute of Medical Science, Loni, Ahmednagar Maharashtra, India
}

\begin{abstract}
Introduction: The family's knowledge and perception of any disease are essential conditions to formulate effective health policies to combat the disease. The tribal populations of India are likely to live discrete hard to reach geographic areas with their common cultural and socio-religious beliefs which are quite different from the general population. The present study was aimed to evaluate attitude with regards to the treatment of tuberculosis among the tribal community in Akole block of Ahmednagar District, Maharashtra. Methods: This was a qualitative cross-sectional study conducted in the tribal community. The study participants were subjected to a well-structured questionnaire which contained questions about the demographics and attitude of the patients concerning tuberculosis. Results: Twenty patients were included in the study, of which $12(60 \%)$ were males while $8(40 \%)$ were females. Majority of study participants opined that the treatment of tuberculosis should be free $(19,95 \%)$, agreed that they should disclose their illness to other people (17, 85\%), were scared (12, 60\%). Only 6 participants felt of being discriminated in the community. It was regarded by most of the participants that pregnant women won't be affected by tuberculosis $(15,85 \%)$. Most of the study participants approached Private practitioner (11, 55\%) and Public health care centre $(8,40 \%)$ initially, but preferred treatment from Governmental facility $(18,90 \%)$ upon the private facility $(2,10 \%)$. Conclusion: There has been a change in attitude and treatment-seeking behaviour of people of Tribal community with regards to tuberculosis. The community needs to be educated with regards to tuberculosis to alleviate fear and eliminate misconceptions. Control of TB in tribal areas continues to face some significant challenges.
\end{abstract}

KEYWORDS: Tuberculosis, Perception, Discrimination, Treatment Seeking Behavior, Tribal Population.

\section{INTRODUCTION}

$\mathrm{T}$ uberculosis (TB) remains a significant public health problem in India, accounting for a quarter of the 8.6 million cases of TB that occur worldwide. Although the drugs are available to cure most TB patients since the 1950s, TB remains still a considerable burden, in resource-poor settings and the world's most important cause of death, especially in India [1].

While recommendations for new interventions are usually based on evidence from the general population, little is known from tribal areas [2].

However, TB is curable and can be prevented. The treatment requires an elaborate drug regime, isolation, understanding of the disease course and its treatment modalities by both patient and caregivers and their co-operation $[3,4]$. The family's knowledge and perception of the disease are essential conditions to formulate effective health policies to combat the disease. The tribal populations of Eastern India live in difficult to access areas and share beliefs that are dissimilar

Correspondence: Dr. Afwan Khan, Pravara Institute of Medical Science, Loni, Ahmednagar Maharashtra, India. Email: afwankhan6g@gmail.com

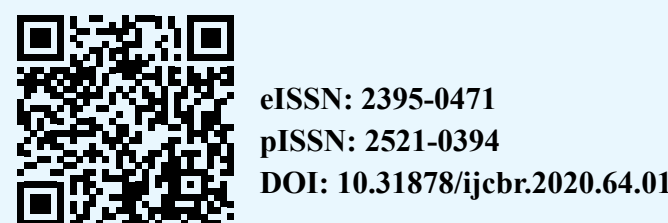

(C) Authors; 2020. (CC BY-NC-SA 4.0)

This is an Open Access article which permits unrestricted non-commercial use, provided the original work is properly cited. 
to that of the population in urban areas. The tribal popoulation are an disadvantaged people who have been away from the civilized world with deprivation of health care facilities [5]. The present study was planned to know the attitude with regards to the treatment of Tuberculosis among Tribal Population in Akole block of Ahmednagar District, Maharashtra.

\section{Material And Methodology}

Study design: The present study was a qualitative cross-sectional

Etthical approval: Approval from the Institutional Ethics Committee was obtained and informed consent obtained from the participants

Study location: Study conducted in the Tribal Population in Akole block of Ahmednagar District, Maharashtra

Study period: during the period of August 2019 to April 2020.

Study population: The tribal population in this is a relatively large number of Tribals viz Mahadev Koli, Thakars, Bhils, and Ramoshies. They speak dialects of Marathi Language. Their major occupation is Agriculture.

Inlcusion criteria: After receiving ethical approval from the Institutional Ethics Committee patients registered with DOTS Centre and receiving treatment for tuberculosis for more than three months and consenting for inclusion in the study were recruited.

Exclusion criteria: Patients of age less than 18 years, and those who have left treatment were excluded from the study.

\section{Sample size: Twenty}

Methodology: The patients were subjected to a well-structured questionnaire which contained questions pertaining to the demographics and attitude of the patients with respect to tuberculosis. In addition, an in-depth interview was taken.

\section{Results}

Twenty patients were included in the study, of which $12(60 \%)$ were males while 8 (40\%) were females. Majority of patients were married $(17$, $85 \%$ ). Most of the patients were farmers by occupation $(14,70 \%)$, followed by workers $(4$, $20 \%$ ). All patients had Pulmonary Tuberculosis, of which one patient was HIV positive.

Table no. 1 shows responses of patients towards attitude regarding the treatment of tuberculosis. The study participants opined that the treatment of tuberculosis should be free $(19,95 \%)$ and agreed that they should disclose their illness to other people $(17,85 \%)$ and did inform their friends and family. They also regarded men to be more likely to get tuberculosis $(16,80 \%)$. Most of the study participants were scared $(12,60 \%)$, one each did not believe and got depressed with the news of a diagnosis of tuberculosis. Only 3 participants (15\%) agreed that the attitude of their friends / family changed when they came to know about the disease, while six participants (30\%) felt of being discriminated in the community, of which males $(12,60 \%)$ were more often discriminated. Only one participant was afraid of losing the job if the diagnosis is known. It was regarded by most of the participants that pregnant women won't be affected by tuberculosis (15, 85\%).

Table 1. Responses of patients towards attitude regarding treatment of tuberculosis.

\begin{tabular}{|l|l|l|}
\hline Attitude towards TB & Frequency & Percentage \\
\hline \multicolumn{3}{|l|}{ 1. Do you think TB patients should be helped with? } \\
\hline a) Free Medicine & 19 & 95 \\
\hline b) Food Support & 1 & 5 \\
\hline $\begin{array}{l}\text { 2. Should people with TB disclose their illness to } \\
\text { other people? }\end{array}$ \\
\hline a) No & 3 & 15 \\
\hline b) Yes & 17 & 85 \\
\hline 3. Who
\end{tabular}

3. Who do you think is more likely to get $\mathrm{TB}$, men and women?

\begin{tabular}{|l|l|l|}
\hline a) Women & 4 & 20 \\
\hline b) Men & 16 & 80 \\
\hline
\end{tabular}

4.How did you feel when you found out that you had TB?

\begin{tabular}{|l|l|l|}
\hline a) Scared & 12 & 60 \\
\hline b) Depressed & 1 & 5 \\
\hline c) Didn't Believe & 1 & 5 \\
\hline d) Other & 6 & 30 \\
\hline
\end{tabular}

5.Did you inform your friends/ family that you had TB?

\begin{tabular}{|l|l|l|}
\hline a) No & 3 & 15 \\
\hline b) Yes & 17 & 85 \\
\hline
\end{tabular}

6.Have your relationships with your friends/ family changed since finding out you have TB?

\begin{tabular}{|l|l|l|}
\hline a) No & 17 & 85 \\
\hline b) Yes & 3 & 15 \\
\hline 7 Are peoplewith TB being discriminated against
\end{tabular}

7.Are people with TB being discriminated against in the community?

\begin{tabular}{|l|l|l|}
\hline a) No & 14 & 70 \\
\hline b) Yes & 6 & 30 \\
\hline 8. Are male or female TB patients more
\end{tabular}

8. Are male or female TB patients more discriminated against?

\begin{tabular}{|l|l|l|}
\hline a) Female & 8 & 40 \\
\hline
\end{tabular}


b) Male

12

60

9. Have you been afraid you may lose your job if it is known you have TB?

\begin{tabular}{|l|l|l|}
\hline a) No & 19 & 95 \\
\hline b) Yes & 1 & 5 \\
\hline
\end{tabular}

10. (For women) Do you think that TB will affect your ability to become pregnant/ have healthy children?

\begin{tabular}{|l|l|l|}
\hline a)No & 15 & 75 \\
\hline b)Yes & 5 & 25 \\
\hline
\end{tabular}

11.(For women) Do you need permission from your husband or relatives to access health services?

\begin{tabular}{|l|l|l|}
\hline a) No & 17 & 85 \\
\hline b) Yes & 3 & 15 \\
\hline
\end{tabular}

Health seeking behavior (patients with TB)

1. Where did you first seek treatment when you became ill?

\begin{tabular}{|l|l|l|}
\hline a) Self-treated & 2 & 10 \\
\hline b) Traditional healer & 0 & 0 \\
\hline $\begin{array}{l}\text { c) Public clinic/ Hospital/ } \\
\text { Health Center }\end{array}$ & 8 & 40 \\
\hline d) Private practitioner & 11 & 55 \\
\hline e) Pharmacist/vendor & 0 & 0 \\
\hline 2.Why?
\end{tabular}

\begin{tabular}{|l|l|l|}
\hline a) Was cheaper & 8 & 40 \\
\hline b) Was closer & 10 & 50 \\
\hline c) More convenient schedule & 1 & 5 \\
\hline d) Better care received & 11 & 55 \\
\hline $\begin{array}{l}\text { e) Better attitude from health } \\
\text { workers }\end{array}$ & 0 & 0 \\
\hline f)Trusted more & 2 & 10 \\
\hline
\end{tabular}

3. Did you seek treatment from somewhere else?

\begin{tabular}{|l|l|l|}
\hline Yes & 13 & 65 \\
\hline 4. From whom & 8 & 40 \\
\hline a)Public Clinic/Hospital & 12 & 60 \\
\hline b) Private Practitioner & \multicolumn{2}{|l|}{} \\
\hline 5. Did you think you had TB? & 20 & 100 \\
\hline No & 20
\end{tabular}

6. Where would you prefer to be treated for TB?

\begin{tabular}{|ll|l|l|}
\hline a) & Government & 18 & 90 \\
\hline b) & Private & 2 & 10 \\
\hline
\end{tabular}

Attitude towards TB Frequency Percentage With regards to health-seeking behaviour, most of the study participants approached Private practitioner $(11,55 \%)$ and Public health care centre $(8,40 \%)$, while two treated themselves. The reason for the behaviour was better care $(11,55 \%)$, approachability $(10,50 \%)$ and cheap treatment $(8,40 \%)$.

None of the participants thought of having Tuberculosis when they first visited the Public clinic $(8,40 \%)$ or Private hospital (12, 60\%). Most of them preferred treatment from Governmental facility $(18,90 \%)$ upon the private facility $(2$, $10 \%)$.

\section{Discussion}

This qualitative study was aimed to evaluate perception of population of tribal people with respect to perception and health seeking behavior towards tuberculosis. Six participants $(30 \%)$ in the present study felt of being discriminated in the community (Table no. 1). Fear of discrimination leads to reluctance in seeking treatment and sharing the health condition with closely knit family and friends. Even so, 17 participants $(85 \%)$ agreed that they should disclose their illness to other people and did inform their friends and family. The discrimination observed in the present study was similar to that observed in a study done in Nepal.[1]

Most of the study participants were scared (12, $60 \%$ ), one each did not believe and got depressed with the news of diagnosis of tuberculosis. It has been reported that owing to Tuberculosis being found commonly among HIV infected patients, the patients of Tuberculosis are defamed considering them to be HIV positive.[2] It is also believed that Tuberculosis is a sexually transmitted disease due to the same notion $[6,7]$.

None of the participants thought of having Tuberculosis when they first visited the Public clinic $(8,40 \%)$ or Private hospital $(12,60 \%)$. Patients often visit to a health care facility later owing to poor knowledge of disease symptomatology. Late identification of symptoms due to lack of knowledge about TB has led to delay in seeking treatment $[8,9]$. Also, most of the initial symptoms of the disease are similar to other common health problems. The results of present study are simiarl to a study done in Uganda[10].

With regards to health seeking behavior, most of the study participants approached Private practitioner $(11,55 \%)$ and Public health care centre $(8,40 \%)$, while two treated themselves. There has been a change in trend of health seeking behavior of the tribal population in contrast to prior practice of avoiding to visit a doctor when health problems occur.

Most of the study participants preferred treatment from Governmental facility $(18,90 \%)$ upon the private facility $(2,10 \%)$. The primary health care workers, being a part of the local community, have a good communication and bond with the tribal population making them 
the best available medium to spread health related awareness. They are at an advantage to recognize high-risk persons and to provide DOTS with better treatment compliance.[11]

Despite increasing discussion on the need for strengthening TB control programme based on strong scientific evidences, little is concretely known about the burden of TB and operational feasibilities to implement in the tribal context. Particularly studies on TB research among tribal population are very limited. Though it is limited in number and its geographic coverage, it provides insight into the level of data and its use. The key challenge is to motivate policy makers to use the available evidence and priority setting tools to direct the limited available resources into the most effective

We tried to take all the information and their attitude about tuberculosis although smaller sample size was the limitation in our study

\section{Conclusion}

There has been a change in attitude and treatment seeking behavior of people of Tribal community with regards to tuberculosis. The community needs to be educated with regards to tuberculosis to alleviate fear and eliminate misconceptions. Control of TB in tribal areas continues to face some major challenges.

\section{Conflict of interest : Nil \\ Source of funding : Nil}

\section{REFERENCES}

1. Rao VG, Bhat J, Yadav R, Sharma R, M Muniyandi, "Research on Tuberculosis in Tribal Areas in India. Indian J Tuberc. 2018;65(1):8-14.

2. Government of India, Revised National TB Control Programme Annual Status Report, TB India, 2013. https://tbcindia.gov.in/ index 1 .php?lang $=1 \&$ level $=1 \&$ sublinkid $=416$ 0\&lid $=2807$

3. Information about Tuberculosis, TB statistics India: TB overall retreatment outcome statistics for India, http://www.tbfacts.org/ tb-statistics-india.html.

4. Vijay S, Balasangameshwara $\mathrm{VH}$, Jagannatha PS. Retreatment outcome of smear positive tuberculosis cases under DOTS in Bangalore. Indian Journal of Tuberculosis. 2002;49:195-204

5. Rao VG, Gopi PG, Bhat J. Pulmonary tuberculosis: a public health problem amongst Saharia, a primitive tribe of Madhya Pradesh, central India. Int $\mathrm{J}$ Infect Dis. 2010;14:e713-e6

6. World Health Organization, Treatment of Tuberculosis. Guidelines for National Programmes, WHO/CDS/TB/2003.313, WHO,Geneva, Switzerland, 3rd edition, 2003.

7. Ottmani SE, Zignol $\mathrm{M}$, Bencheikh $\mathrm{N}$, La asri L, Chaouki N, MahjourJ. Results of cohort analysis by category of tuberculosis retreatment cases in Morocco from 1996 to 2003. International Journal of Tuberculosis and Lung Disease. 2006;10(12):1367-72

8. Ministry of Health \& Family Welfare, Guidelines on Programmatic Management of Drug Resistant TB (PMDT) in India, Ministry of Health \& Family Welfare, New Delhi, India. 2012,http:// tbcindia.gov.in/ WriteReadData/ 1892s / 8320929355Guidelines\%20for\%20 PMDT\%20in\%20India\%20-\%20May \%20 2012.pdf. 8 Tuberculosis Research and Treatment

9. Ministry of Health \& Family Welfare, Training Module forMedical Practitioners, Ministry of Health \& Family Welfare, New Delhi, India, 2010, http:// tbcindia.nic.in / Write Read Data / 1892s / 5949760355Training\%20Module\%20 for $\% 20$ Medical\%20-Practitioners.pdf.

10. World Health Organization. South-East Asia Regional Office. Tuberculosis in the SouthEast Asia Region, Delhi," Tech. Rep.SEATB-302, WHO SEARO, New Delhi, India, 2008.

11. Dooley KE, Lahlou O, Ghali I. Risk factors for tuberculosis treatment failure, default, or relapse and outcomes of retreatment in Morocco. BMC Public Health. 2011;11:140 